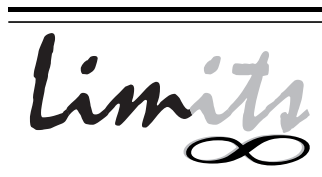

J. Math. and Its Appl.

ISSN : $1829-605 \mathrm{X}$

Vol. 4, No. 2, November 2007, 9-19

\title{
KOMPUTASI PENGENDALIAN TUBERKULOSIS DUA STRAIN DENGAN METODE BEDA HINGGA
}

\author{
Lukman Hanafi $^{1}$, Mardlijah ${ }^{2}$, E. Wahyuni ${ }^{3}$ \\ Jurusan Matematika \\ FMIPA Institut Teknologi Sepuluh Nopember, Surabaya \\ ${ }^{1}$ lukman@matematika.its.ac.id
}

\begin{abstract}
Abstrak
Pengendalian tuberkulosis dua strain (laten dan menular) merupakan salah satu aplikasi dari teori pengendalian optimal. Tujuan dari pengendalian ini adalah untuk mengurangi jumlah grup tuberkulosis yang kebal / tahan terhadap obat. Salah satu penanganan yang dapat dilakukan agar jumlah grup strain tersebut berkurang adalah dengan menggunakan kemoterapi. Namun penderita tuberkulosis merasa hal ini cukup memakan waktu dan biaya tinggi. Pada makalah ini dibahas penanganan tuberkulosis yang optimal pada model tersebut dengan kontrol yang digunakan adalah yang mewakili dua tipe penanganan dengan mempertimbangkan strategi kontrol optimal yang dipengaruhi waktu dan akan diselesaikan secara numerik dengan menggunakan skema beda hingga. Katakunci: Tuberkulosis, pengendalian optimal, beda hingga
\end{abstract}




\section{Pendahuluan}

Pada saat ini program kontrol Tuberkulosis (TB) telah difokuskan pada kemoterapi karena kurangnya vaksin efektif. Penanganan antibiotik pada pasien TB aktif memerlukan waktu yang jauh lebih lama dan biaya yang lebih tinggi daripada pada mereka yang terinfeksi dengan TB sensitif tetapi belum berkembang menjadi penyakit. Selain kemoterapi, BTA (Basil Tahan Asam) juga masih banyak digunakan, namun BTA masih terdapat kekurangan. Kurangnya kesesuaian dalam penanganan tidak hanya mengakibatkan kekambuhan tetapi juga perkembangan TB yang kebal terhadap antibiotik. Pengurangan kasus TB yang sensitif pada obat-obatan bisa diperoleh dengan case holding dan case finding, menunjuk pada aktivitas dan teknik yang dipakai untuk memastikan case holding keteraturan pemakaian obat dengan waktu yang cukup agar bisa sembuh. Case finding menunjuk pada identifikasi individu yang secara laten terinfeksi TB sensitif yang beresiko tinggi mengembangkan penyakit dan yang mendapatkan kemajuan dengan adanya intervensi pencegahan. Penanganan pencegahan ini akan mengurangi insiden TB yang sensitif pada obat-obatan dan dengan demikian secara tidak langsung mengurangi insiden TB yang tahan pada obat-obatan.

Biaya dalam memfasilitasi case finding dan case holding berbeda-beda tergantung banyak faktor. Misalnya pada case holding bisa sangat menantang karena adanya fakta bahwa kemoterapi harus dilakukan selama beberapa bulan untuk memastikan adanya kesembuhan yang permanen, namun pasien biasanya sudah merasa sembuh hanya setelah beberapa pekan penanganan dan seringkali berhenti mengkonsumsi obat. Pada case finding, diutamakan pencegahan perkembangan penyakit dengan terapi pencegahan pada orang yang secara laten terinfeksi dengan TB sensitif. Terdapat beberapa metode case finding. Case finding aktif, yang menunjuk pada metode identifikasi kasus TB dimana kontak pasien/penyedia inisiatif pertama dilakukan oleh penyedia layanan kesehatan, sedangkan case finding pasif, yang menunjuk pada metode identifikasi kasus TB dimana kontak pasien/penyedia inisiatif pertama dilakukan oleh pasien.

Tujuan dari penelitian ini adalah untuk mengoptimalkan penanganan TB agar mengurangi jumlah grup strain yang tahan pada obat Batasan yang digunakan dalam permasalahan ini adalah model yang digunakan 
menganggap bahwa individu dalam tahap laten mengembangkan TB aktif pada nilai tertentu, proporsi individu yang dirawat dengan TB aktif tidak mengakhiri perawatan, dan individu bisa terinfeksi hanya melalui kontak dengan individu yang penyakitnya menular.

Pada makalah ini dibahas tentang strategi kontrol optimal yang dipengaruhi waktu dengan case holding dan case finding pada model TB dua strain yang dikembangkan didalamnya. Usaha case finding digabungkan dengan menambahkan syarat kontrol yang mengidentifikasi dan menyembuhkan satu fraksi individu laten sehingga jumlah individu yang penyakitnya berkembang bisa berkurang. Usaha case holding digabungkan dengan menambahkan syarat kontrol yang bisa mengurangi jumlah kegagalan perawatan individu dengan TB sensitif aktif sehingga insiden adanya TB yang tahan pada obat-obatan bisa dikurangi dan akan diselesaikan secara numerik dengan menggunakan skema beda hingga.

\section{Model Sistem}

TB dua strain dapat dinyatakan alam model matematika berikut :

$$
\begin{aligned}
& S=\Lambda-\beta_{1} S \frac{I_{1}}{N}-\beta^{*} S \frac{I_{2}}{N}-\mu S \\
& \dot{L_{1}}=\beta_{1} S \frac{I_{1}}{N}-\left(\mu+k_{1}\right) L_{1}-u_{1}(t) r_{1} L_{1}+\left(1-u_{2}(t)\right) p r_{2} I_{1}+\beta_{2} T \frac{I_{1}}{N}-\beta^{*} L_{1} \frac{I_{2}}{N} \\
& \dot{I_{1}}=k_{1} L_{1}-\left(\mu+d_{1}\right) I_{1}-r_{2} I_{1} \\
& \dot{L_{2}}=\left(1-u_{2}(t)\right) q r_{2} I_{1}-\left(\mu+k_{2}\right)+\beta^{*}\left(S+L_{1}+T\right) \frac{I_{2}}{N} \\
& \dot{I}_{2}=k_{2} L_{2}-\left(\mu+d_{2}\right) I_{2} \\
& \dot{T_{2}}=u_{1}(t) r_{1} L_{1}=\left(1-u_{2}(t)\right)(p+q) r_{2} I_{1}-\beta_{2} T \frac{I_{1}}{N}-\beta^{*} T \frac{I_{2}}{N}-\mu t
\end{aligned}
$$

Akan ditemtukan pengontrol $u_{1}, u_{2}$ sehingga

$$
J\left(u_{1}, u_{2}\right)=\int_{0}^{t_{f}}\left[L_{2}(t)+I_{2}(t)+\frac{B_{1}}{2} u_{1}^{2}(t)+\frac{B_{2}}{2} u_{2}^{2}(t)\right] d t
$$

minimal. Atau bisa dituliskan maksimalkan

$$
J\left(u_{1}, u_{2}\right)=-\int_{0}^{t_{f}}\left[L_{2}(t)+I_{2}(t)+\frac{B_{1}}{2} u_{1}^{2}(t)+\frac{B_{2}}{2} u_{2}^{2}(t)\right] d t
$$


dengan

$S$ : berpotensi terkena TB

$L_{1}$ : laten, terinfeksi dengan TB umum, tetapi tidak menular

$I_{1}$ : bersifat menular dengan TB khas

$L_{2}$ : laten, terinfeksi dengan TB strain yang tahan obat tetapi tidak menular

$I_{2}$ : bersifat menular dengan TB yang tahan pada obat

$T$ : dirawat (dengan efektif)

$N: S+L_{1}+I_{1}+L_{2}+I_{2}+T$

$\lambda$ : jumlah rekrutmen

$\beta_{1}$ : jumlah individu yang berpotensi tertular

$\beta_{2}$ : individu yang dirawat menjadi terinfeksi oleh individu yang TB-nya menular

$\beta^{*}$ : jumlah individu yang tidak terinfeksi menjadi terinfeksi oleh satu TB tahan

obat yang menular.

$\mu$ : jumlah kematian alami per kapita.

$d_{1}$ : jumlah kematian per kapita yang disebabkan oleh penyakit pada TB umum

$d_{2}$ : jumlah kematian per kapita yang disebabkan oleh penyakit pada TB yang tahan obat.

$k_{1}$ : jumlah individu yang meninggalkan kasus laten

$k_{2}$ : jumlah individu yang terjangkit TB menular

$r_{1}$ : jumlah perawatan individu yang menderita TB laten yang menular

$r_{2}$ : jumlah perawatan individu yang menderita TB umum yang menular

$u_{1}(t)$ : mewakili fraksi TB umum pada individu laten yang teridentifikasi dan yang akan diberikan perawatan.

$1-u_{2}(t)$ : usaha yang mencegah kegagalan perawatan pada penderita TB umum yang menular

$p+q$ : proporsi mereka yang dirawat karena menderita TB menular dan tidak menyempurnakan perawatan $(p+q \leq 1)$.

Berdasarkan kebutuhan yang dinyatakan dalam bentuk plant dapat dirancang kreteria performance matematis atau performance index, selanjutnya diupayakan untuk menentukan solusi yang mengoptimalkan performance index ini.

\section{Pembahasan}

Pada prinsipnya, tujuan dari optimal control adalah menentukan signal yang akan diproses dalam plant dan memenuhi konstrain fisik. Pada waktu yang sama dapat ditentukan ekstrim (maksimum/minimum) yang sesuai dengan kreteria performance index. Perhatikan permasalahan berikut ini:

$$
\max \int_{t_{0}}^{t_{1}} f(x, u, t) d t
$$


dengan kendala

$$
\dot{x}=g(x, u, t), x\left(t_{0}\right)=x_{0} a \leq u \leq b
$$

Persamaan Hamiltonian yang terbentuk $H=f(x, u, t)+\lambda(g(x, u, t))$. . .. Supaya optimal maka harus memenuhi persamaan

1. $\frac{\partial H}{\partial u}=f_{u}(x, u, t)+\lambda(g(x, u, t))=0$.

2. Persamaan keadaan: $\dot{x}=\frac{\partial H}{\partial \pi}, \dot{\lambda}=-\frac{\partial H}{\partial x}, x\left(t_{0}\right)=x_{0}$ dan $\lambda\left(t_{1}\right)=0$.

Akan tetapi, sebelum melakukan penyelesaian optimal control pada suatu model maka terlebih dahulu dilakukan identifikasi mengenai eksistensi optimal control. Jika plant dalam keadaan kontinu dan terbatas, serta fungsi pada integral performance index concave dan terbatas maka eksistensi optimal control dapat diidentifikasi. Tetapi, kontrol yang dapat diterima harus dalam keadaan konvex dan tertutup.

\section{Penyelesaian optimal kontrol}

$$
\begin{aligned}
H= & L_{2}(t)+I_{2}(t)+\frac{B_{1}}{2} u_{1}^{2}(t)+\frac{B_{2}}{2} u_{2}^{2}(t)+\lambda_{1}\left(\Lambda-\beta_{1} S \frac{I_{1}}{N}-\beta^{*} S \frac{I_{2}}{N}-\mu S\right) \\
& +\lambda_{2}\left(\beta_{1} S \frac{I_{1}}{N}-\left(\mu+k_{1}\right) L_{1}-u_{1}(t) r_{1} L_{1}+\left(1-u_{2}(t)\right) p r_{2} I_{1}+\beta_{2} T \frac{I_{1}}{N}\right. \\
& -\beta^{*} L_{1} \frac{I_{2}}{N}-\beta^{*} L_{1} \frac{I_{2}}{N}+\lambda_{3}\left(k_{1} L_{1}-(\mu+d) I_{1}-r_{2} I_{1}\right) \\
& +\lambda_{4}\left(\left(1-u_{2}(t)\right) q r_{2} I_{1}-\left(\mu+k_{2}\right) L_{2}+\beta^{*}\left(S+L_{1}+T\right) \frac{I_{2}}{N}\right) \\
& +\lambda_{5}\left(k_{2} L_{2}-\left(\mu+d_{2}\right) I_{2}\right) \\
& +\lambda_{6}\left(u_{1}(t) r_{1} L_{1}+\left(1-\left(1-u_{2}(t)\right)(p+q) r_{2} I_{1}-\beta_{2} T \frac{I_{1}}{N}-\beta^{*} T \frac{I_{2}}{N}-\mu T\right)\right.
\end{aligned}
$$

Berdasarkan prinsip optimal didapat $: \frac{\partial H}{\partial u_{1}}=0$ dan $\frac{\partial H}{\partial u_{2}}=0$, sehingga diperoleh :

1. untuk optimal control $u_{1}^{*}$.

$$
\begin{aligned}
& \frac{\partial H}{\partial u_{1}}=B_{1} u_{1}-\lambda_{2} r_{1} L_{1}+\lambda_{6} r_{1} L_{1}=0 \\
& B_{1} u_{1}=\lambda_{2} r_{1} L_{1}-\lambda_{6} r_{1} L_{1} \\
& u_{1}^{*}(t)=\frac{1}{B_{1}}\left(\lambda_{2}-\lambda_{6}\right) r_{1} L_{1}^{*}
\end{aligned}
$$

Karena $a_{1}<u_{1}^{*}<b_{1}$, maka dapat ditulis

$$
u_{1}^{*}(t)=\min \left(\max \left(a_{1}, \frac{1}{B_{1}}\left(\lambda_{2}-\lambda_{6}\right) r_{1} L_{1}^{*}, b_{1}\right)\right. \text {. }
$$


2. untuk optimal control $u_{2}^{*}$.

$$
\begin{aligned}
& \frac{\partial H}{\partial u_{2}}=B_{2} u_{2}-p r_{2} I_{1} \lambda_{2}-q r_{2} I_{1} \lambda_{4}+(p+q) r_{2} I_{1} \lambda_{6}=0 \\
& B_{2} u_{2}=p r_{2} I_{1} \lambda_{2}+q r_{2} I_{1} \lambda_{4}-(p+q) r_{2} I_{1} \lambda_{6} \\
& u_{2}^{*}(t)=\frac{1}{B_{2}}\left(p \lambda_{2}+q \lambda_{4}-(p+q) \lambda_{6}\right) r-2 I_{1}^{*}
\end{aligned}
$$

Karena $a_{2}<u_{2}^{*}<b_{2}$, maka dapat ditulis

$u_{2}^{*}(t)=\min \left(\max \left(a_{2}, \frac{1}{B_{2}}\left(p \lambda_{2}+q \lambda_{4}-(p+q) \lambda_{6}\right) r-2 I_{1}^{*}, b_{2}\right)\right.$. untuk optimal control $u_{2}^{*}$.

\section{Solusi numerik}

Persamaan state diselesaikan dengan menggunakan metode beda hingga maju.

$$
\begin{aligned}
S_{i+1} & =\frac{S_{i}+h \Lambda}{1+h\left(\beta_{1} \frac{I_{1}^{\prime}}{N}-\beta^{*} \frac{I_{2}^{\prime}}{N}-\mu\right)} \\
L_{1}^{i+1} & =\frac{L_{1}^{i}+h\left(\beta_{1} S_{i+1} \frac{I_{1}^{i}}{N}+\left(1-u_{2}^{i}(t)\right) p r_{2} I_{1}^{i}+\beta_{2} T_{i} \frac{I_{1}^{i}}{N}\right)}{1+h\left(\left(\mu+k_{1}\right)+u_{1}^{i}(t) r_{1}+\frac{I_{2}^{i}}{N}\right)} \\
I_{1}^{i+1} & =\frac{I_{1}^{i}+h k_{1} L_{1}^{i+1}}{1+h\left(\mu+d_{1}+r_{2}\right)} \\
L_{2}^{i+1} & =\frac{L_{2}^{i}+h\left(\left(1-u_{2}^{i}(t)\right) q r_{2} I_{1}^{i+1}+\beta^{*}\left(S_{i+1}+L_{1}^{i+1}+T_{i}\right) \frac{I_{2}^{i}}{N}\right)}{1+h\left(\mu+k_{2}\right)} \\
I_{2}^{i+1} & =\frac{I_{2}^{i}+h\left(k_{2} L_{2}^{i+1}\right)}{1+h\left(\mu+d_{2}\right)} \\
T_{i+1} & =\frac{T_{i}+h\left(u_{1}^{i}(t) r_{1} L_{1}^{i+1}+\left(1-\left(1-u_{2}^{i}(t)\right)(p+q)\right) r_{2} I_{1}^{i+1}\right)}{1+h\left(\beta_{2} \frac{I_{1}^{i+1}}{N}+\beta^{*} \frac{I_{2}^{i+1}}{N}+\mu\right)}
\end{aligned}
$$


Persamaan adjoin diselesaikan dengan menggunakan metode beda hingga mundur.

$$
\begin{aligned}
& \lambda_{1}^{n-i-1}=\frac{\lambda_{1}^{n-i}+h\left(\lambda_{2}^{n-i}\left(\beta_{1} \frac{I_{1}^{i+1}}{N}\right)+\lambda_{4}^{n-i}\left(\beta^{*} \frac{I_{2}^{i+1}}{N}\right)\right)}{1+h\left(\beta_{1} \frac{I_{1}^{i+1}}{N}+\beta^{*} \frac{I_{2}^{i+1}}{N}+\mu\right)} \\
& \lambda_{2}^{n-i-1}=\frac{\lambda_{2}^{n-i}+h\left(\lambda_{3}^{n-i}\left(k_{1}\right)+\lambda_{4}^{n-i}\left(\beta^{*} \frac{I_{2}^{i+1}}{N}\right)+\lambda_{6}^{n-i}\left(u_{1}^{i}(t) r_{1}\right)\right)}{1+h\left(\left(\mu+k_{1}+u_{1}^{i}(t) r_{1}+\beta^{*} \frac{I_{2}^{i+1}}{N}\right)\right.} \\
& \lambda_{3}^{n-i-1}=\frac{1}{1+h\left(\mu+d_{1}+r_{2}\right)} \lambda_{3}^{n-i}+\left[h\left(\lambda_{1}^{n-i-1}\left(-\beta_{1} \frac{S_{i+1}}{N}\right)\right)\right. \\
& +\left(h \lambda_{2}^{n-i-1}\left(\beta_{1} \frac{S_{i+1}}{N}+\left(1-u_{2}^{i}(t)\right) p r_{2}-\beta_{2} \frac{T_{i+1}}{N}\right)\right) \\
& +\left(\lambda_{4}^{n-i}\left(-\left(1-u_{2}^{i}(t)\right) q r_{2}\right)\right. \\
& \left.\left.+\lambda_{6}^{n-i}\left(\left(1-\left(1-u_{2}^{i}(t)\right)(p+q)\right) r_{2}-\beta_{2} \frac{T_{i+1}}{N}\right)\right)\right] \\
& \lambda_{4}^{n-i-1}=\frac{\lambda_{4}^{n-i}+h\left(1+\lambda_{5}^{n-i}\left(k_{2}\right)\right)}{1+h\left(\mu+k_{2}\right)} \\
& \lambda_{5}^{n-i-1}=\frac{\lambda_{5}^{n-i}+h\left(1+\lambda_{1}^{n-i-1}\left(-\beta^{*} \frac{S_{i+1}}{N}\right)+\lambda_{2}^{n-i-1}\left(-\beta^{*} \frac{L_{1}^{i+1}}{N}\right)\right)}{1+h\left(\mu+d_{2}\right)} \\
& \frac{+\lambda_{4}^{n-i-1}\left(-\beta^{*} \frac{S^{i+1}+L_{1}^{i+1}+T^{i+1}}{N}\right)+\lambda_{6}^{n-i}\left(-\beta^{*} \frac{T_{i+1}}{N}\right)}{1+h\left(\mu+d_{2}\right)} \\
& \lambda_{6}^{n-i-1}=\frac{\lambda_{6}^{n-i}+h\left(\lambda_{2}^{n-i-1}\left(\beta_{2} \frac{I_{1}^{i+1}}{N}\right)+\lambda_{4}^{n-i-1}\left(-\beta_{2} \frac{I_{2}^{i+1}}{N}\right)\right)}{1+h\left(\beta_{2} \frac{I_{1}^{i+1}}{N}+\beta_{2} \frac{I_{2}^{i+1}}{N}+\mu\right)} \\
& u_{1}^{i+1}=\min \left(\max \left(0.05, \frac{1}{B_{1}}\left(\lambda_{2}^{n-i-1}-\lambda_{6}^{n-i-1}\right) r_{1} L_{1}^{i+1}, 0.95\right)\right. \\
& u_{2}^{i+1}=\min \left(\operatorname { m a x } \left(0.05, \frac{1}{B_{2}}\left(p \lambda_{2}^{n-i-1}+q \lambda_{4}^{n-i-1}-(p+q) \lambda_{6}^{n-i-1}\right) r_{2} I_{1}^{i+1}\right.\right.
\end{aligned}
$$

Dari gambar yang diberikan, diasumsikan bahwa faktor penyeimbang $B_{2}$ yang diasosiasikan dengan kontrol $u_{2}$ lebih besar atau sama dengan faktor penyeimbang $B_{1}$ yang diasosiasikan dengan kontrol $u_{1}$. Anggapan ini berdasarkan fakta bahwa 
biaya yang diasosiasikan dengan kontrol $u_{1}$ akan mengikutsertakan biaya program pemilahan dan penanganan, dan biaya yang diasosiasikan dengan $u_{2}$ akan mengikutsertakan biaya penanganan pasien di rumah sakit atau mengirim orang untuk mengawasi pasien agar melengkapi masa perawatannya. Pada gambar, faktor bobot, $B_{1}=50$ dan $B_{2}=200$, dipilih untuk menggambarkan strategi penanganan optimal. Parameter lain diberikan pada tabel dibawah ini.

Tabel 1: Parameter dan Nilainya

\begin{tabular}{|l|l|}
\hline Parameter & Nilai \\
\hline$\beta 1$ & 13 \\
\hline$\beta 2$ & 13 \\
\hline$\beta^{*}$ & 0.029 \\
\hline$M u$ & 0.0143 \\
\hline$d 1$ & 0 \\
\hline$d 2$ & 0 \\
\hline$k 1$ & 0.5 \\
\hline$k 2$ & 1 \\
\hline$r 1$ & 2 \\
\hline$r 2$ & 1 \\
\hline$p$ & 0.4 \\
\hline$q$ & 0.1 \\
\hline$N$ & 30000 \\
\hline$\Lambda$ & $N$ \\
\hline$S(0)$ & $(76 / 120) N$ \\
\hline$L 1(0)$ & $(36 / 120) N$ \\
\hline$I 1(0)$ & $(4 / 120) N$ \\
\hline$L 2(0)$ & $(2 / 120) N$ \\
\hline$I 2(0)$ & $(1 / 120) N$ \\
\hline$T(0)$ & $(1 / 120) N$ \\
\hline
\end{tabular}

Gambar 1 menunjukkan stategi penanganan optimal untuk kasus diatas. Pada gambar atas, control $u_{1}$ (kurva padat) dan control $u_{2}$ (kurva putus-putus) diplot sebagai fungsi waktu. Pada gambar 2, fraksi individu yang terinfeksi TB tahan obat, $\left(L_{2}+I_{2}\right) / N$, dengan control (kurva padat) dan tanpa kontrol (kurva putusputus) diplot. Pada gambar ini $N=30000$ dan $\beta^{*}=0.029$ yang dipilih. Parameter 
Tabel 2: Parameter komputasi

\begin{tabular}{|l|l|l|}
\hline Parameter Komputasi & Symbol & \\
\hline Waktu akhir & $t_{f}$ & 5 tahun \\
\hline Durasi waktu & $D t$ & 0.1 tahun \\
\hline Batas atas kontrol & & 0.95 \\
\hline Batas bawah kontrol & & 0.05 \\
\hline $\begin{array}{l}\text { Faktor berat yang diasosiasikan } \\
\text { dengan } u_{1}\end{array}$ & $B_{1}$ & 50 \\
\hline $\begin{array}{l}\text { Faktor berat yang diasosiasikan } \\
\text { dengan } u_{2}\end{array}$ & $B_{2}$ & 200 \\
\hline
\end{tabular}

lainnya terdapat pada table 1 dan 2 .. Jumlah total individu, $L_{2}+I_{2}$ yang terinfeksi TB yang tahan pada obat-obatan pada waktu akhir $t_{f}=5$ (tahun) adalah 997 dalam kasus dengan kontrol didalamnya dan 4175 pada kasus tanpa kontrol di dalamnya, dan kasus total TB tahan obat dicegah pada akhir program kontrol adalah 3178 (= $4175-997)$.

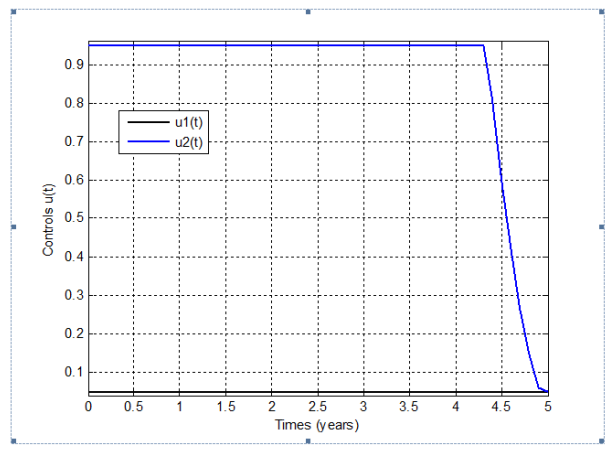

Gambar 1: Kontrol $u_{1}$ dan $u_{2}$

\section{Kesimpulan}

Dari analisa yang dilakukan pada model TB dua strain, maka dapat diperoleh kesimpulan sebagai berikut : 


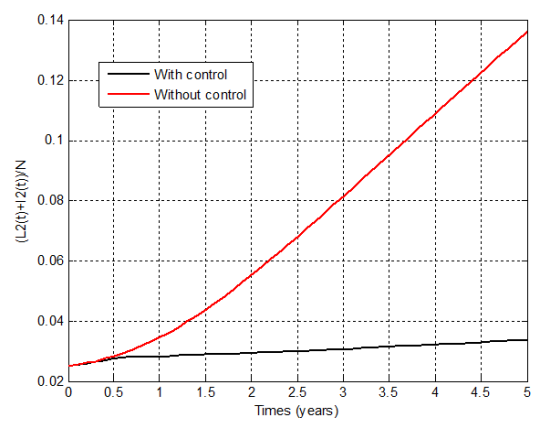

Gambar 2: Perbandingan populasi dengan kontrol dan tanpa kontrol

1. Pada analisis control optimal dapat diketahui bahwa :kontrol TB dua strain adalah

$$
\begin{gathered}
u_{1}^{*}(t)=\min \left(\max \left(a_{1}, \frac{1}{B_{1}}\left(\lambda_{2}-\lambda_{6}\right) r_{1} L_{1}^{*}, b_{1}\right)\right. \\
u_{2}^{*}(t)=\min \left(\max \left(a_{2}, \frac{1}{B_{2}}\left(p \lambda_{2}+q \lambda_{4}-(p+q) \lambda_{6}\right) r_{2} I_{1}^{*}, b_{2}\right)\right.
\end{gathered}
$$

2. Hasil perhitungan numerik menunjukkan keefektifan kontrol yang ada bisa mengurangi jumlah penderita TB sebanyak 3178 orang dalam kurun waktu 5 tahun.

\section{Pustaka}

[1] Chaulet, P., Treatment of Tuberculosis: Case holding Until Cure, WHO/TB/83. Word Healt Organization, Geneva, 141, 1983.

[2] Chavez, C., and Z. Feng, To Treat Or Not To Treat : The Case of Tuberculosis, J. Mathematical Biology, , 35, 629-659, 1997.

[3] Jung, E., Lenhart, S., and Feng, Z., Optimal Control Of Treatment In A Two-Strain Tuberculosis Model, Discrete And Continuous Dynamical Sistems Series B Volume 2 number 4"., pp. 473-482, 2002.

[4] Lewis, F., Optimal Control, Georgia : School Of Enginering Georgia Institute of Technology Atlanta, 1986.

[5] Pontryagin, L.S , Boltyanskii, V. G, Gamkrelidze, R. V, and Mishchenko, E.F., The Mathematical Theory Of Optimal Processe, Wiley, New York, 1962. 
[6] Reichman, L.B., and Hershfield, E.S., Tuberculosis A Comprehensive International Appoarch, Dekker, New York, 2000.

[7] Supriyanto, Runge-Kutta Orde Empat, (www.supriyanto.fisika.ui.edu/laci04/komputasi_edisi_3.pdf), 2006.

[8] WHO, Tuberculosis Strategy and Operation, (www.who.int/gtb/dots), 2000. 